\title{
RECALIBRATING A SUGARCANE CROP MODEL USING THERMAL INFRARED DATA
}

\author{
Julien Morel ${ }^{1}$, Valentine Lebourgeois ${ }^{2}$, Jean-François Martiné $e^{3}$, Pierre Todoroff ${ }^{1}$, Agnès Béguét, Michel \\ Petit $^{5}$
}

\author{
${ }^{1}$ UR SCA, Cirad, 7 chemin de l'Irat, FR-97410 Saint-Pierre, La Réunion \\ ${ }^{2}$ UMR TETIS, Cirad, 7 chemin de l'Irat, FR-97410 Saint-Pierre, La Réunion \\ ${ }^{3}$ UR SCA, Cirad, Station de la Bretagne, FR-97400 Saint-Denis, La Réunion \\ ${ }^{4}$ UMR TETIS, Cirad, 500 rue Jean-François Breton, FR-34000 Montpellier, France \\ ${ }^{5}$ IRD, 911 avenue Agropolis, FR-34394 Montpellier Cedex 05, France
}

\begin{abstract}
Coupling remotely sensed data with crop model is known to improve the estimation of crop variables by the model. The recalibration coupling approach tends to reduce the differences between observation and simulation by optimizing the value of one of the model's parameter. In this study, we used this approach with a sugarcane model and Crop Water Stress Index calculated using remotely sensed thermal infrared data in order to optimize the value of the root depth parameter thanks to measured and simulated AET/MET ratio. The effect of the root depth recalibration has also been assessed on the yield estimation, which showed good trends with a significant enhancement of the estimated yield.
\end{abstract}

Index terms - thermal infrared, recalibration, crop model, sugarcane, yield

\section{INTRODUCTION}

MOSICAS model simulates the growth of a sugarcane plot in controlled conditions (i.e, with controlled water and optimum nitrogen inputs, and without any impacts of pests and diseases on the crop), based on both a crop growth module and a water-balance module. A major challenge when working in agricultural conditions is the estimation of the model's parameters such as the root depth or the soil available water content that can be depleted from the root zone before moisture stress occurs.
Coupling crop models with remote sensing data is a promising approach to overcome this limitation [1-4]. Remote sensing data are known to be linked with the actual value of different crop state variables $[5,6]$. These remotely sensed crop state variables can then be used for the adjustment of the model's parameters in order to obtain a simulation in agreement with remotely-sensed observations. Among other coupling approaches, recalibration optimizes the value of one of the model's parameter. In this paper, we assessed the use of an empirical Crop Water Stress Index (CWSI, corresponding to 1-AET/MET, respectively Actual Evapotranspiration and Maximum Evapotranspiration) [7, 8] derived from remotely sensed thermal infrared data to recalibrate the root depth parameter used in the water balance module of MOSICAS.

\section{MATERIAL AND METHODS}

The experiment took place in southern part of Reunion Island from 2007 to 2008 . This region is characterized by a tropical climate with mean annual rainfall of $1007 \mathrm{~mm}$ year $^{-1}$. The trial is based on a total of seven sugarcane plots (four in 2007, three in 2008) with contrasted water treatments (rainfed versus irrigated treatments). The trial plots were planted with R570 sugarcane cultivar on cambisol. 
Using thermal infrared data and ambient meteorological conditions (vapor pressure deficit and air temperature) allows to convert canopy temperature in a water stress index corresponding to 1 -AET/MET. This index is restricted to full cover canopy to avoid soil influence, and has to be measured under clear sky conditions.

Daily measurements of thermal infrared and meteorological data were made over a three months period corresponding to full canopy development. Due to cloudy conditions, only twenty-eight values of CWSI were computed empirically as presented in [9] using thermal infrared radiometers (IRR-P infrared radiometer, Apogee instruments Inc.) viewing canopy in a vertical mode. The CWSI values were grouped into six periods of homogeneous climatic conditions. In the end, we kept the averaged value of CWSI.

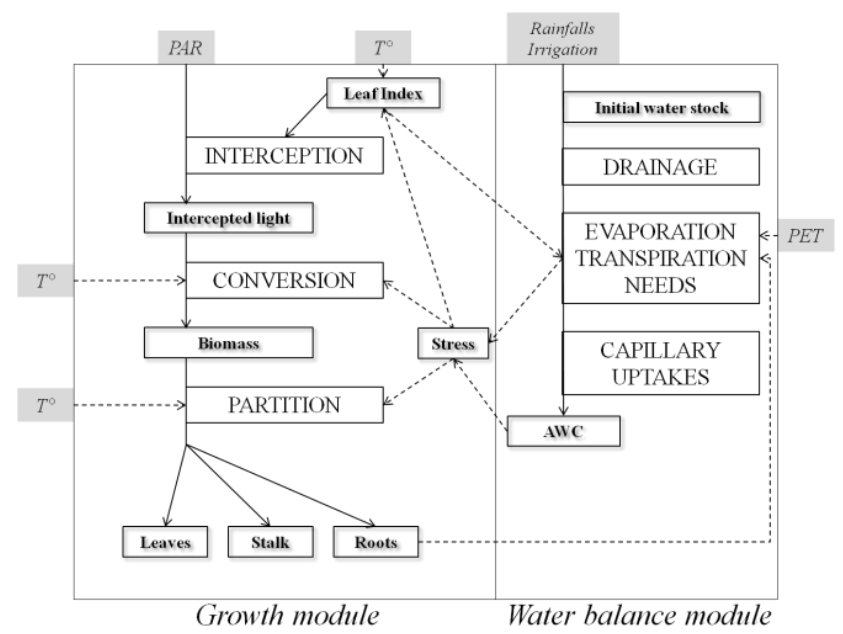

Fig. 1. Simplified schema of the main components of MOSICAS.

MOSICAS [10, 11] is a sugarcane semi empirical dynamic crop growth model. It simulates at a daily timestep the growth of a uniform sugarcane plot as a function of climatic variables (rainfalls, potential evapotranspiration, global radiation and mean temperature) and with specific soil and sugarcane cultivar parameters. It is based on both a water balance and a growth module (Fig. 1). The water balance module is adapted from the water-balance module of the Ceres model [12] to compute a AET and MET ratio. A satisfaction water index is then computed. The growth module uses this water satisfaction index, mean temperature and global radiation to compute the dry matter production that will be allocated to the different organs of the plant.
It has been shown for this study [9] that CWSI and AET/MET showed significant correlation. We used the model's outputs of AET and MET to compare simulated values of AET/MET and measured ones.

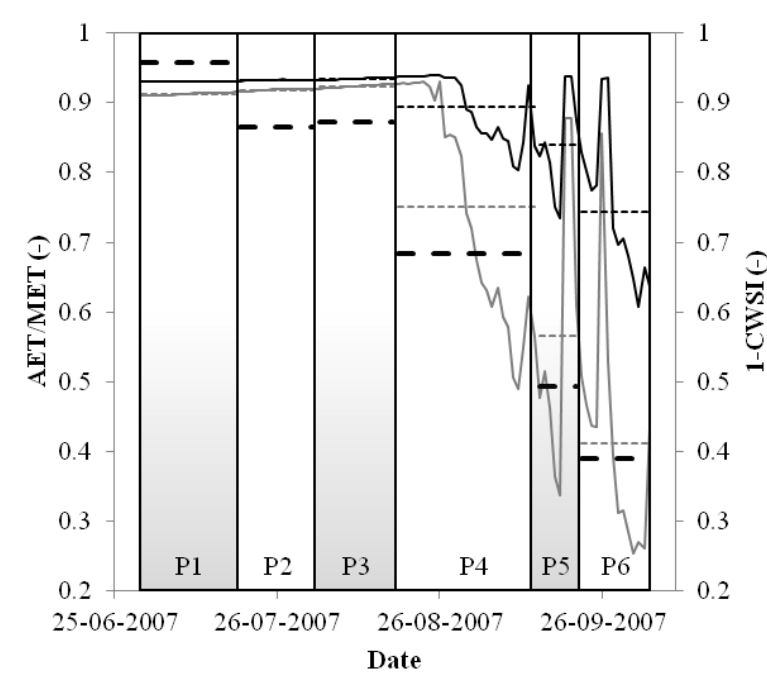

Fig. 2. Comparison of AET/MET for two simulations at different root depths with measured 1-CWSI. The grey and black solid lines represent simulated AET/MET $(\mathrm{RD}=80$ and $160 \mathrm{~cm}$ respectively). The dashed lines represent the mean value for each period. The bold dashed black line represents the mean values of 1-CWSI measurements for each period.

Since all climatic variables are known in this study, misestimations of the water stress index should come from the estimation of soil's parameters. The total available water is directly linked to the available water capacity (AWC) and the root depth parameter (RD). AWC value has been measured to $72.5 \mathrm{~mm} / \mathrm{m}$ in laboratory. RD estimation is uneasy since there is no method to measure it quickly or cheaply. We used the recalibration approach to find an optimized value of the root depth, where the root mean squared error between measured 1-CWSI and simulated AET/MET is minimized. For each period, simulated AET/MET values were averaged and weighted by the duration of each period (Fig. 2). For each plot and each root depth, the root mean squared error over the six periods was calculated based on the differences between mean AET/MET and mean 1-CWSI. In the end, considering that all our plots belong to the same pedologic unit, we computed the mean of RMSE of each plot for each root depth. 


\section{RESULTS AND DISCUSSION}

For each plot, seventeen simulations were run, with different values of root depths ranging from $30 \mathrm{~cm}$ to $250 \mathrm{~cm}$. Mean values of RMSE were computed for each root depths.

Fig. 3 shows that the optimized value of the root depth parameter, at trial scale, is $80 \mathrm{~cm}$. The initial value of the root depth parameter was $160 \mathrm{~cm}$.

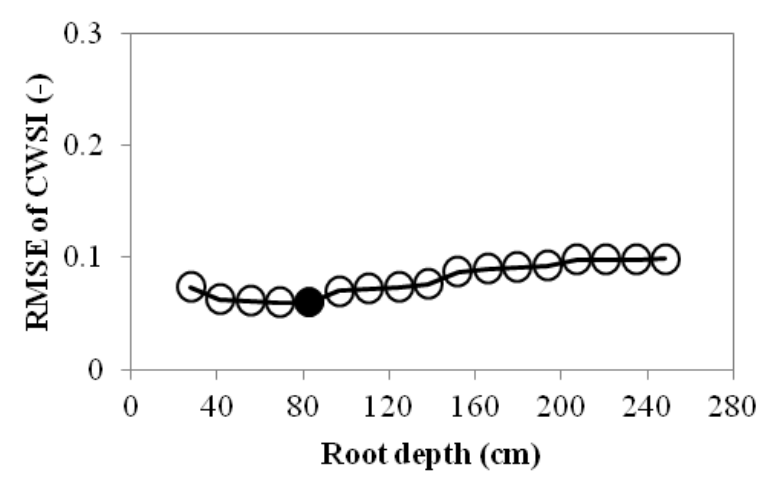

Fig. 3. Root mean squared error between simulated AET/MET and 1-CWSI for all plots. The filled circle shows the root depth value with the minimal RMSE.

We also computed yield estimations. We compared the simulated yield with the observed one for each plot (Fig. 4). All plots show significant increase of the accuracy of the estimated yield, except for plot number 5. This overestimation may be due to phenomena that are not water-balance dependant. Leaf Area Index data analysis should lead to a better understanding of the biomass production of this plot.

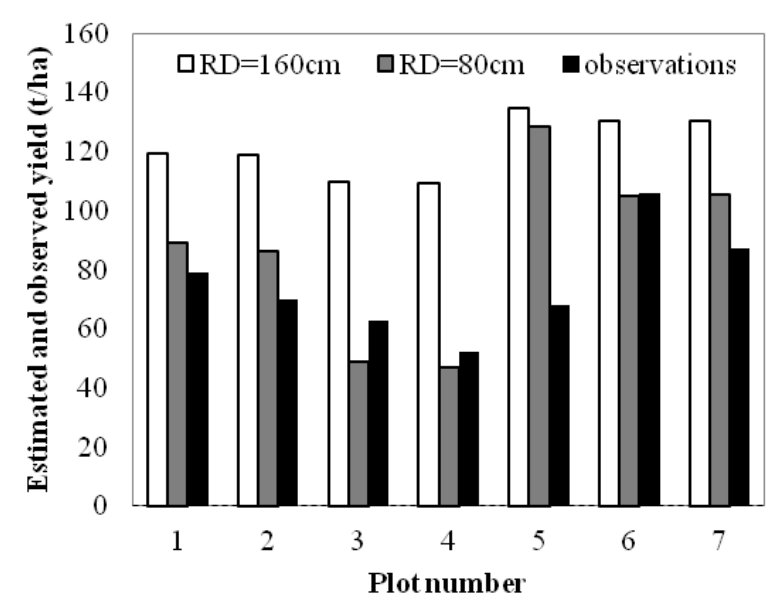

Fig. 4. Comparison of the observed and simulated yields.
Fig. 5 shows the root mean squared error of the estimated yield for the initial value of the root depth $(160 \mathrm{~cm})$ and the enhanced value $(80 \mathrm{~cm})$. There is significant increase of the accuracy of the yield estimation by the model.

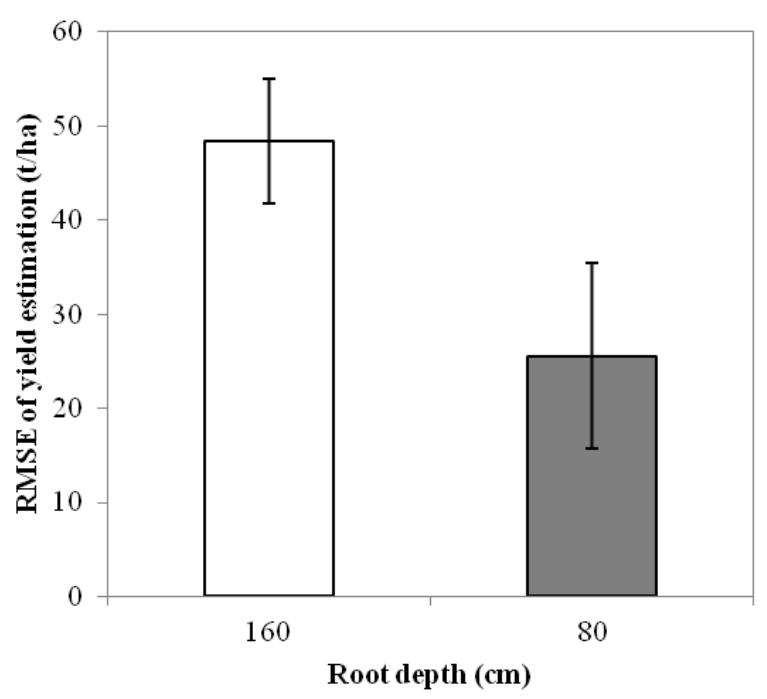

Fig. 5. Comparisons of root mean squared error in the yield estimation for the initial root depth $(160 \mathrm{~cm})$ and the optimized value $(80 \mathrm{~cm})$.

\section{CONCLUSIONS}

Our results showed that the estimation of the water stress index by sugarcane crop model MOSICAS can be significatively improved with the recalibration coupling approach. An enhanced root depth of $80 \mathrm{~cm}$ has been computed for the pedologic unit of the trial.

This study has also showed that the optimization of the root depth parameter also has a significant influence on the estimated yield, passing from a root mean squared error of $48.5 \mathrm{t} / \mathrm{ha}$ to $25.5 \mathrm{t} / \mathrm{ha}$. However, the current configuration of the model did not allow us to work with optimizing methods (i.e, genetic algorithms, simulated annealing, etc.). One of the next steps would be to change the structure of the model in order to apply an optimization algorithm.

This method should also be tested on larger areas and various types of soils across Reunion Island to provide a database of recommended root depth for yield estimations at the regional scale. 


\section{REFERENCES}

[1] Dorigo, W.A., et al., "A review on reflective remote sensing and data assimilation techniques for enhanced agroecosystem modeling." International Journal of Applied Earth Observation and Geoinformation, 2007. 9(2): p. 165-193.

[2] de Wit, A.J.W. and C.A. van Diepen, "Crop model data assimilation with the Ensemble Kalman filter for improving regional crop yield forecasts." Agricultural and Forest Meteorology, 2007. 146(1-2): p. 38-56.

[3] Wang, Y.-P., et al., "Large-area rice yield forecasting using satellite imageries." International Journal of Applied Earth Observation and Geoinformation, 2010. 12(1): p. 27-35.

[4] Casa, R., et al., "Forcing a wheat crop model with LAI data to access agronomic variables: Evaluation of the impact of model and LAI uncertainties and comparison with an empirical approach." European Journal of Agronomy, 2012. 37(1): p. 1-10.

[5] Bégué, A., "Leaf area index, intercepted photosynthetically active radiation, and spectral vegetation indices: A sensitivity analysis for regular-clumped canopies." Remote Sensing of Environment, 1993. 46(1): p. 45-59.

[6] Zheng, G. and L.M. Moskal, "Retrieving Leaf Area Index (LAI) Using Remote Sensing:
Theories, Methods and Sensors." Sensors, 2009. 9(4): p. 2719-2745.

[7] Idso, S.B., et al., "Normalizing the stress-degreeday parameter for environmental variability." Agricultural Meteorology, 1981. 24(0): p. 45-55.

[8] Jackson, R.D., et al., "Canopy temperature as a crop water stress indicator." Water Resources Research, 1981. 17(4): p. 1133-1138.

[9] Lebourgeois, V., et al., "Towards using a thermal infrared index combined with water balance modelling to monitor sugarcane irrigation in a tropical environment." Agricultural Water Management, 2010. 97(1): p. 75-82.

[10] Martiné, J.-F., "Modélisation de la production potentielle de canne à sucre en zone tropicale, sous conditions hydriques et thermiques contrastées. Applications du modèle." $P h D$ Thesis, 2003. p. 132.

[11] Martiné, J.-F. "Analysis and forecasting of the sucrose content of sugarcane crops during the harvest period in Reunion Island." in 26th Congress of the International Society of Sugar Cane Technologists. 2007. Durban, South Africa.

[12] MacKinnon, J.C., ed. "CERES-Maize: A simulation model of maize growth and development." C.A. Jones and J.R. Kiniry (editors). Computers and Electronics in Agriculture. Vol. 2. 1987, Texas A\&M University Press, College Station, TX. 194. 